\author{
Military Technical College \\ Kobry El-Kobbah, \\ Cairo, Egypt.
}

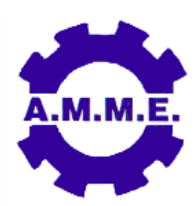

$17^{\text {th }}$ International Conference on Applied Mechanics and Mechanical Engineering.

\title{
BUOYANCY BOXES (SPONSONS) EFFECTS ON SEA KEEPING QUALITIES OF RORO/PAX SHIPS
}

\author{
Y. Welaya ${ }^{1}$, M. A. Kotb ${ }^{2}$ and T. M. Hassan ${ }^{3}$
}

\begin{abstract}
A ship sea keeping quality is usually adjudged in regards to many parameters like vessel motions thus affect passengers comfort or cargo safety. In this paper, a numerical analysis for on Motion sickness incidence and vertical acceleration levels. The analysis shows that in different Sea states, the sponsons seems to have a positive effect in reducing motion sickness as well as for the vertical acceleration, although this advantage seems to have minor effects but could prove useful as a step towards more comfort and healthy seagoing ship.
\end{abstract}

\section{KEY WORDS}

Ship Motion, Sea keeping, Hydrodynamics, Motion Sickness.

1 Department of Marine Engineering and Naval Architecture, Faculty of Engineering, Alexandria University, Egypt.

2 Department of Marine Engineering and Naval Architecture, Faculty of Engineering, Alexandria University, Egypt; currently on leave Arab academy for science, technology and maritime Transport, Abukir, Alexandria Egypt

3 Department of Marine Engineering, College of Engineering \& Technology, Arab Academy for Science and Technology \& Maritime Transport, Abukir Egypt. 


\section{NOMENCLATURE}

$\begin{array}{ll}Z & \text { linear motion amplitude from equation of motion in } \mathrm{m} \\ \zeta & \text { Wave motion amplitude in } \mathrm{m} \\ \theta & \text { Rotational motion amplitude from equation of motion in rad } \\ \omega & \text { Wave circular frequency in rad/s } \\ \omega \text { e } & \text { Encounter frequency in rad/s } \\ \mathrm{H}_{1 / 3} & \text { Significant wave height in } \mathrm{m} \\ \mathrm{H}_{\text {char }} & \text { Characteristic wave height in } \mathrm{m} \\ \bar{T} & \text { Average wave period in } \mathrm{s} \\ \text { erf } & \text { Error function } \\ \left|\ddot{S}_{3}\right| & \text { Vertical acceleration averaged over a half motion cycle in } \mathrm{m} / \mathrm{s} 2\end{array}$

\section{INTRODUCTION}

When it comes to the ship's design process, many of the aspects are usually investigated apart from one another; structural strength, ship motion, stability, trim, resistance and propulsion are some of these aspects [1]. In the last 60 years it became more important to evaluate marine structures on its sea keeping qualities [2], this is very vital for navy vessels and passenger ships as ship's motion may inflict the greatest impact on ship's capability.

Motion sickness is usually one of the parameters that needs to be investigated since they have a great effect on the crew's performance and also on passengers' comfort, early attempts by O'Hanlan and McCawley [3] to derive a mathematical expression to define the percentage of subjects who vomited within two hours after experimentation over 300 personnel under the name of Motion Sickness Incidence (MSI), while Graham developed what is commonly known in Human comfort criteria levels as Motions Induced Interruptions (MII) [4].

Many experimental studies were carried out to investigate the effect of vessel's motion on human behavior and illness degree, Lawther et. al. gathered records of motion sickness occurrences from the behavior of 20,029 passengers and motion on 9 different vessels surveyed on 114 voyages to help in such study [5]. Recent attempts vary from investigation of different passenger vessels performance like Chih-Chung Fang's attempts on a high-speed catamaran ferry [6] Tezgodan's et. al. helped by showing the procedures needed for calculating operability index of ships using sea keeping analysis and performed such method on catamaran case study comparing to human comfort criteria [7] like ISO 2631/1-1997 [8].

Scamardella et. al analyzed different hull forms under different headings to propose a new parameter under the name of Overall motion sickness incidence (OMSI) defined as the mean MSI value on the main deck [9].

This paper presents a study for the effect of ship widening using side buoyancy boxes on Motion Sickness Incidence as well as Vertical accelerations levels on a RORO/Pax vessel, Simulation was calculated using Maxsurf Motions Advanced comparing the effects between both cases A \& B (before and after conversion) respectively. 


\section{METHOD}

For predicting ship's behavior under different sea states, many numerical software are in use today. In this paper, Maxsurf Motion Advanced is a commercial software part of the Maxsurf ship analysis suite is used to predict such behavior. It is a diffractionradiation solver based on Panel method. Knowing the incident wave potential, it uses Boundary element method (BEM) which is a well-established numerical technique for analysis of many engineering problems, particularly linear and second order ones.

It was in the mid of the past century, where it was discovered that the ship can be treated as the electronic filter methodology, in short the ship is a "black box" of wave inputs and motion outputs, the response of the ship is usually expressed by what's commonly known transfer function or Response Amplitude Operators (RAO) where they are calculated as follows: -

For linear motion, wave amplitude, linear motion transfer function is given by:

$$
R A O_{z}=\frac{z}{\zeta}
$$

While for angular motion, wave slope; angular motion transfer function is:

$$
R A O_{z}=\frac{\theta}{k \zeta}
$$

Vertical acceleration, wave acceleration; acceleration transfer function is defined as:

$$
R A O_{z}=\frac{a}{\omega_{e}^{2} \zeta}
$$

The Bretschneider or ITTC, two parameter spectrum is defined in equation (4)

$S_{\text {ITTC }}(\omega)=\frac{A}{\omega^{5}} \exp \left(\frac{-B}{\omega^{4}}\right)$

where $S_{\text {ITTC }}(\omega)=\frac{A}{\omega^{5}} \exp \left(\frac{-B}{\omega^{4}}\right)$

and $B=\frac{691}{\bar{T}^{4}}$

Moreover, it can be deduced that $\mathrm{H}_{\text {char }} \approx \mathrm{H}_{1 / 3}$

The one-parameter Bretschneider spectrum is similar to the two parameter spectrum but is defined in terms of wave height only, as follows:

$S_{\text {Bret(1param) }}(\omega)=\frac{A}{\omega^{5}} \exp \left(\frac{-B}{\omega^{4}}\right)$

where A is Philip's constant, given by:

$$
A=8.11 \times 10^{-3} g^{2}
$$


and $\mathrm{B}=3.11 / \mathrm{H}_{1 / 3}{ }^{2}$

Vertical acceleration is one of the important parameters to be noticed when considering the behavior of ships considering Motion Sickness, other acceleration components seem to have minor effects on MSI., Motion induced interruptions are relatively affected by lateral accelerations.

Motion Sickness incidence is defined as mentioned above as the percentage of subjects who vomited within a predetermined time period, Maxsurf Motions Advanced calculates MSI for 2 hours' fixed exposure time as that mentioned in Lloyd's as follows:

$M S I \%=100 \times\left(0.5+\operatorname{erf}\left(\frac{\log _{10}\left(\frac{\left|\ddot{s}_{3}\right|}{g}\right)-\mu_{M S I}}{0.4}\right)\right)$

where $\quad \mu_{M S I}=0.819+2.32\left(\log _{10} \omega_{e}\right)^{2}$

\section{CASE STUDY}

A typical passenger Roll On/ Roll Off (RORO/Pax) ship was chosen as a case study for assessing the MSI. The Ship has undergone a widening process using side buoyancy boxes (sponsons) $1 \mathrm{~m}$ wide, the ship's hull was based on a real RORO M/V SHEHRAZADE. The ship particulars are shown in Table 1. The ship with and without sponsons were investigated at $4.5 \mathrm{~m}$ draft at an even keel state. The vessel's frame of reference was set to for 0 point at base line with +ve values going up, amidship and center line were the datum for longitudinal \& transverse where forward and starboard sides define +ve values respectively.

A table of offsets was constructed using the available general arrangement plan and ship lines drawings and some transverse section plans. The ships sponsons were drawn alone then was fitted on the drawing of original ship in order to obtain a clear and more accurate hull form for the new modified case, Figure 1 shows the NURB surfaces generated for both hull and sponsons.

For the present analysis, 3 Sea state codes were picked since they represent the most likely conditions experienced by the vessel during its voyages, Bretschneider spectrum was also picked and the characteristic wave height was set according to the mean value of the world meteorological organization sea state code as shown in Table 2.

The Water depth was set for deep water $(500 \mathrm{~m})$ deep, and for the frequency range, $(0.2 \mathrm{rad} / \mathrm{s}$ frequency till $-5 \mathrm{rad} / \mathrm{s}$ ) A total number of 31 frequencies were used.

\section{RESULTS AND DISCUSSION}

The results for the vertical acceleration root mean square (RMS) are plotted in figures 2 to 28 below for all 3 remote locations. Case A describes ship's behavior before conversion while case $B$ is the vessel after the conversion process. 
For both cases, it can be noticed that the MSI acceleration level tends to diminish to zero at increased frequencies starting from $2.5 \mathrm{rad} / \mathrm{s}$ and above in all the upcoming figures, this is logical since any vessels response tends to decrease with the increase of frequency since very short waves tends to have the same effect as a calm sea state.

Considering the bridge remote location point, the vertical accelerations did not exceed the limits for ISO 2 hours and 30 minutes' exposure, however in moderate waves, it can be noted that sponsons had a positive effect when were acceleration had dropped slightly in case B than that of case A, this drop in acceleration can be seen clearly in fig. 2 when the wave direction was 90 degrees, it seems that the widening process helped in decreasing such motion although case A was exceeding the 8 hours boundary.

When facing the $3.25 \mathrm{~m}$ height waves (rough), fig. 5 shows that case $B$ dropped below the 8 hours' limit while the original ship was already exceeding again when wave was beam heading, fig. 6 and 7 shows almost a resonance between case $A$ and $B$ except that bow quartering rough wave seems to increase above the long period exposure limit.

Case $B$ when facing $5 \mathrm{~m}$ waves shows a rarity of exceeding the first limit but only with very low encounter frequency but still dropped below case A as in fig. 8, fig. 9 shows both ships exceeding the 8hrs limit while fig. 10 shows the sponsons fittings have decreased the acceleration with the ship slightly than its predecessor, this can be explained due to sponsons fitting, the increase in ship's beam and change in shape seems to have magnified the vessels response when facing beam and bow quartering very rough waves.

When investigating the acceleration level at the accommodation pt. 1 during the moderate wave phase, figs. 11,12 and 13 showed that the increase in width helped to decrease the vertical acceleration specially when waves came from the ships side at 90 degree angles.

$3.25 \mathrm{~m}$ waves showed almost an enhancement where values of acceleration dropped below the 8 hours' exposure limit for case B than its former case in fig. 14, while cases $A$ and $B$ are below the limit in figures 15,16 and 19, Figs 17 and 18 showed a surge in case $B$ at lower frequencies where such increase can be explained as a result of the sponsons change in shape and sudden change in ship's breadth.

Accommodation location 2 picked on the aft of the ship showed that R.M.S of the vertical acceleration never exceeded the 8 hours' boundary on both cases in figure 20 and 21 while in rough beam waves the boundary has been reached at a frequency range $0.8-1 \mathrm{rad} / \mathrm{sec}$ (figure 23) and same case appeared in beam very rough waves (figure 26), head waves seem to have the lowest effect on vertical acceleration (Figs 22,25 and 28).

The MSI \% has been indicated in figures (29, 30, and 31) a difference between MSI \% when ship was widened and that before conversion, although the highest MSI\% ever noticed was $11 \%$ on bridge when facing the $5 \mathrm{~m}$ bow quartering wave, It is noted in Fig. 29 that head waves shows no significant change for all 3 remote locations while the widening process decreased the MSI percentage on all cases with a maximum on 
bridge by almost $5 \%$ (Beam rough wave case), thus enhancing crew performance and operability. Accommodation point 1 had a slight decrease in MSI by $3 \%$ when facing rough waves. The location picked for Accommodation point 2 on the aft of the vessel seems to have no effects at all, Probably the widened buoyancy boxes with its geometry at the aft and the increase in width lead to the damping of the motion at such location hence decreasing vertical acceleration and Motion Sickness incidence as in Figures 30 and 31 .

\section{CONCLUSION}

The investigation of the Ship widening using buoyancy boxes has been investigated and the following points have been concluded.

a) Concerning the MSI the widening process seems to lower that index for all locations and regardless of the wave heading and height with a maximum of $5 \%$ during rough beam wave at the bridge point.

b) The difference in sponsons geometry between fore and aft for the sponsons seems to have had an effect in reducing the MSI \% when facing beam waves.

c) The vertical acceleration compared to all ISO criteria never exceed the 2 hours and 30 mins' limits.

d) The values of vertical acceleration decreased due to widening with lower frequencies for almost all locations.

e) A surge in the value of the vertical acceleration for case B appears at much lower frequencies when facing $5 \mathrm{~m}$ beam waves at the bridge and forward accommodation point due to sudden change in the hull shape forward.

\section{REFERENCES}

[1] D. G. Watson, Practical ship design vol. 1: Elsevier, 1998.

[2] J. Journee and J. Pinkster, Introduction in ship hydromechanics, 2002.

[3] J. F. O'Hanlon and M. E. McCauley, "Motion sickness incidence as a function of the frequency and acceleration of vertical sinusoidal motion," DTIC Document1973.

[4] R. Graham, "Motion-Induced Interruptions as Ship Operability Criteria," Naval Engineers Journal, vol. 102, pp. 65-71, 1990.

[5] A. LAWTHER and M. J. GRIFFIN, "Motion sickness and motion characteristics of vessels at sea," Ergonomics, vol. 31, pp. 1373-1394, 1988.

[6] C.-C. Fang and H.-S. Chan, "An investigation on the vertical motion sickness characteristics of a high-speed catamaran ferry," Ocean engineering, vol. 34, pp. 1909-1917, 2007.

[7] T. Tezdogan, A. Incecik, and O. Turan, "Operability assessment of high speed passenger ships based on human comfort criteria," Ocean Engineering, vol. 89, pp. 32-52, 2014.

[8] I. O. f. Standardization, Mechanical vibration and shock-Evaluation of human exposure to whole-body vibration-Part 1: General requirements: The Organization, 1997. 
[9] A. Scamardella and V. Piscopo, "Passenger ship seakeeping optimization by the Overall Motion Sickness Incidence," Ocean Engineering, vol. 76, pp. 86-97, 2014.

\section{TABLES \& FIGURES.}

Table 1. Ship Particulars.

\begin{tabular}{|c|c|}
\hline Ship Particular & Value (m) \\
\hline LBP & 119.26 \\
\hline LwL & 124 \\
\hline Depth & 12 \\
\hline Draft & 4.5 \\
\hline Beam Ext. & 19.77 \\
\hline Beam Extents after sponsons & 21.7 \\
\hline
\end{tabular}

Table 2. Remote points locations.

\begin{tabular}{|c|c|c|c|c|}
\hline No & Point Name & $\begin{array}{c}\text { Longitudinal } \\
\text { pos. }\end{array}$ & $\begin{array}{c}\text { Transverse } \\
\text { pos. }\end{array}$ & $\begin{array}{c}\text { Vertical } \\
\text { pos. }\end{array}$ \\
\hline 1 & Bridge & 42 & 2 & 23.5 \\
\hline 2 & Accom.1 & 25 & 2 & 15 \\
\hline 3 & Accom. 2 & -25 & -2 & 19 \\
\hline
\end{tabular}

Table 3. Wave description, heights and average periods.

\begin{tabular}{|c|c|c|}
\hline $\begin{array}{c}\text { Wave } \\
\text { Description }\end{array}$ & Characteristic Height $(\mathbf{m})$ & Average period $(\mathbf{m})$ \\
\hline Moderate & 1.875 & $5.293 \mathrm{~s}$ \\
\hline Rough & 3.25 & $6.969 \mathrm{~s}$ \\
\hline Very rough & 5 & $8.644 \mathrm{~s}$ \\
\hline
\end{tabular}




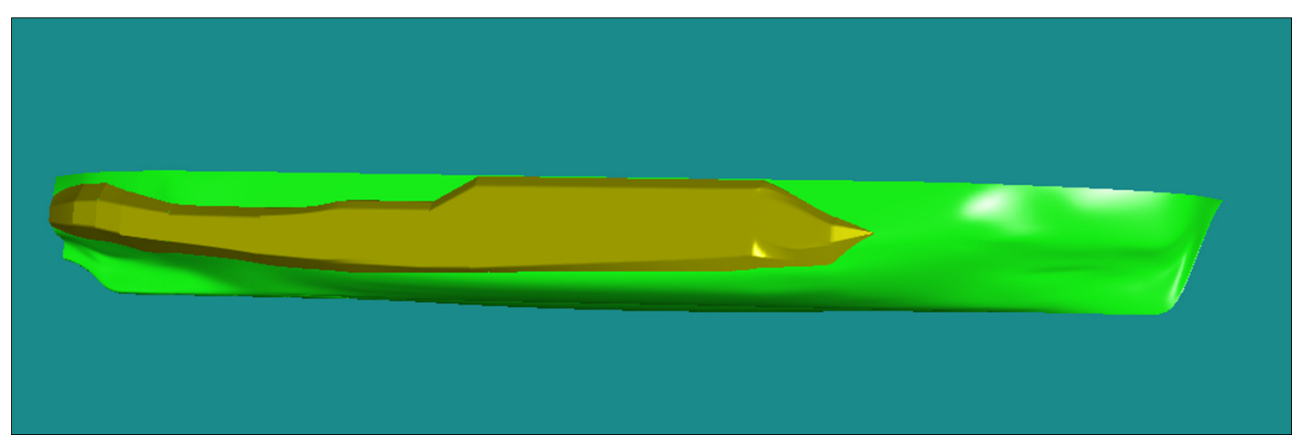

Fig. 1. Ship's hull after sponsons fitting.

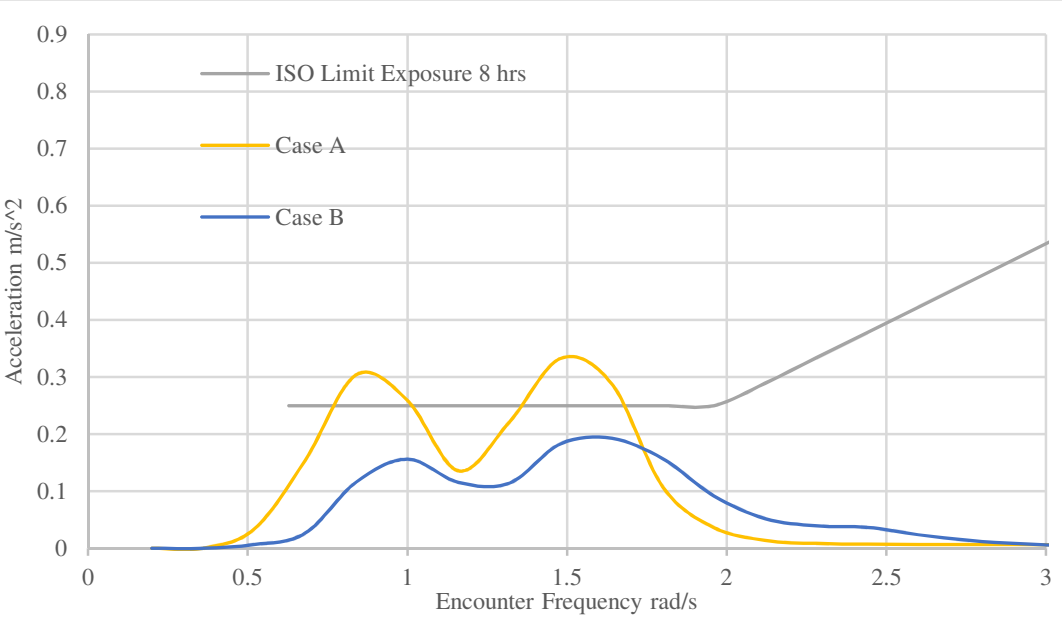

Fig. 2. Bridge in moderate beam waves.

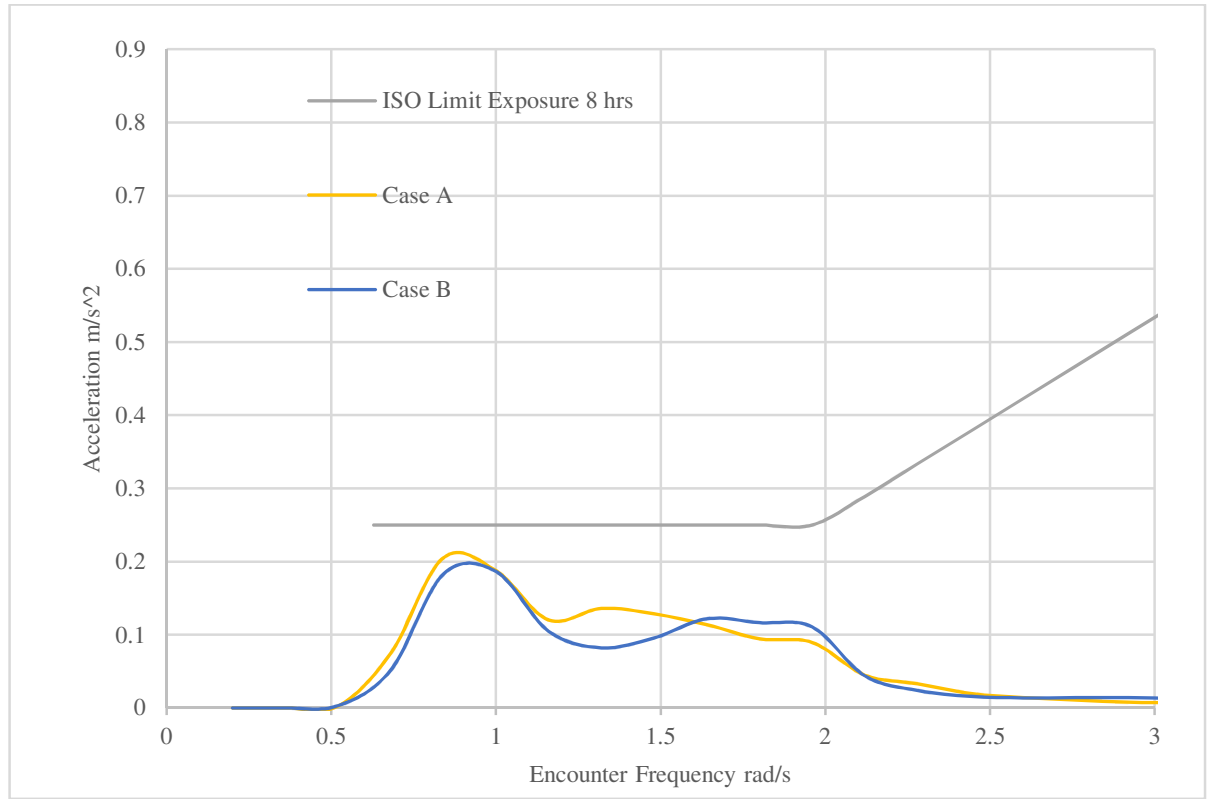

Fig. 3. Bridge in moderate bow quartering waves. 


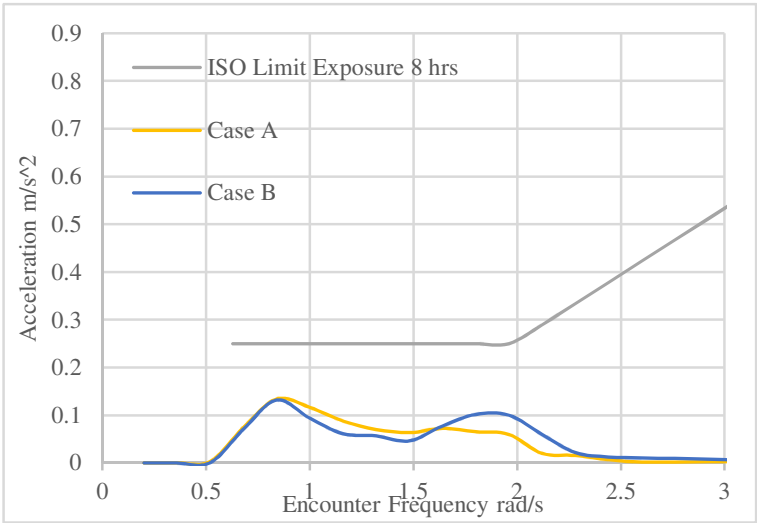

Fig. 4. Bridge in moderate head waves.

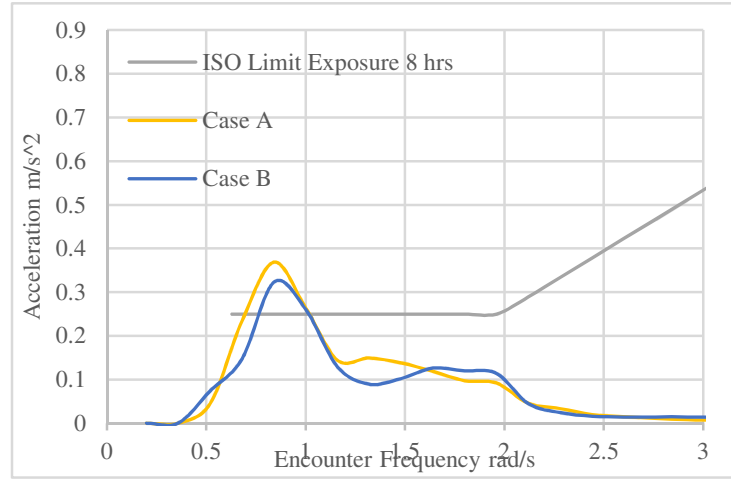

Fig. 6. Bridge in rough bow quartering waves.

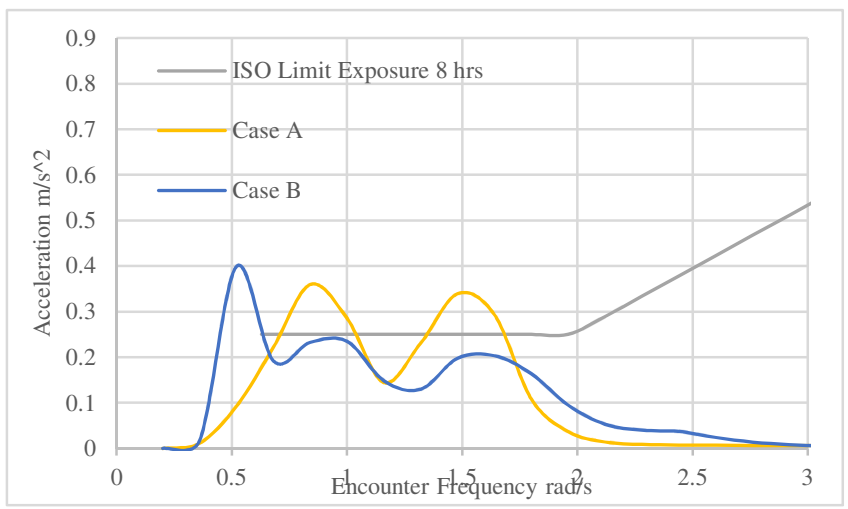

Fig. 8. Bridge in Very Rough Beam waves.

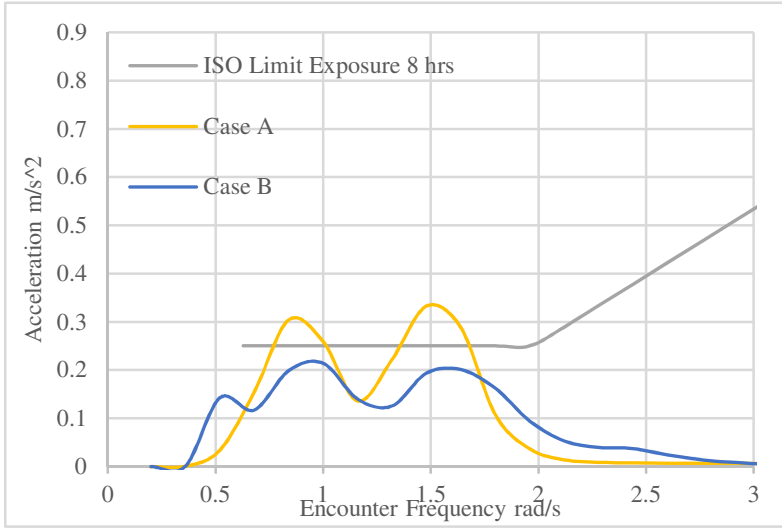

Fig. 5. Bridge in rough beam waves.

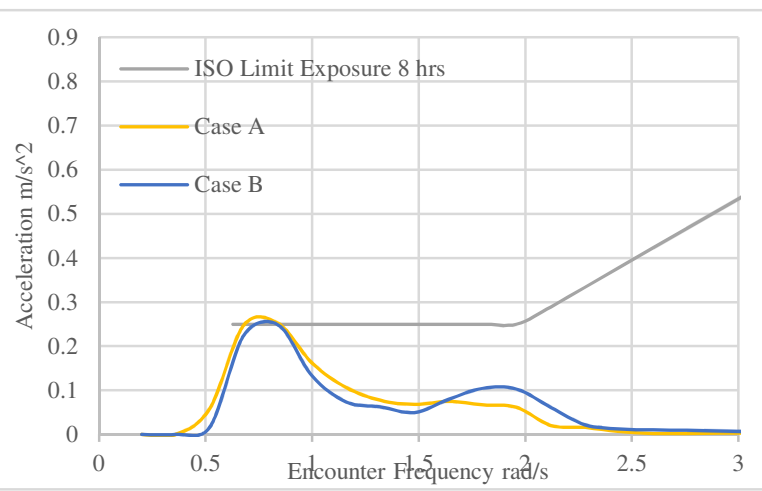

Fig. 7. Bridge in rough head waves.

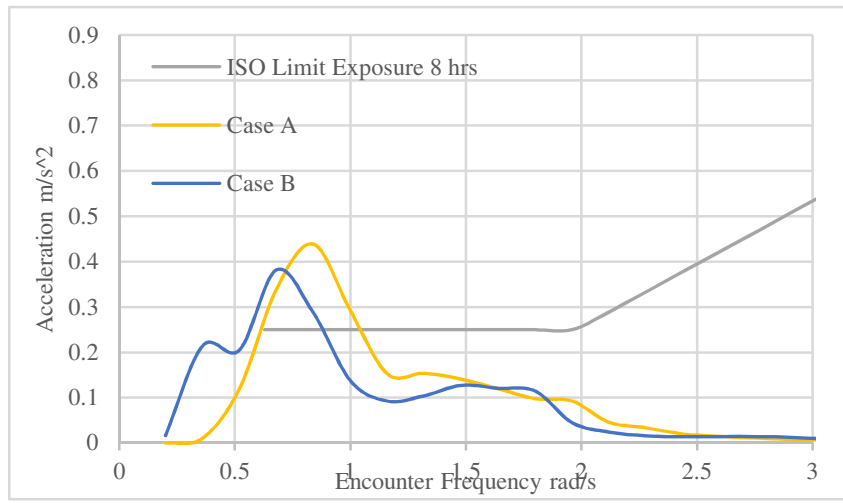

Fig. 9. Bridge in very rough bow quartering waves. 


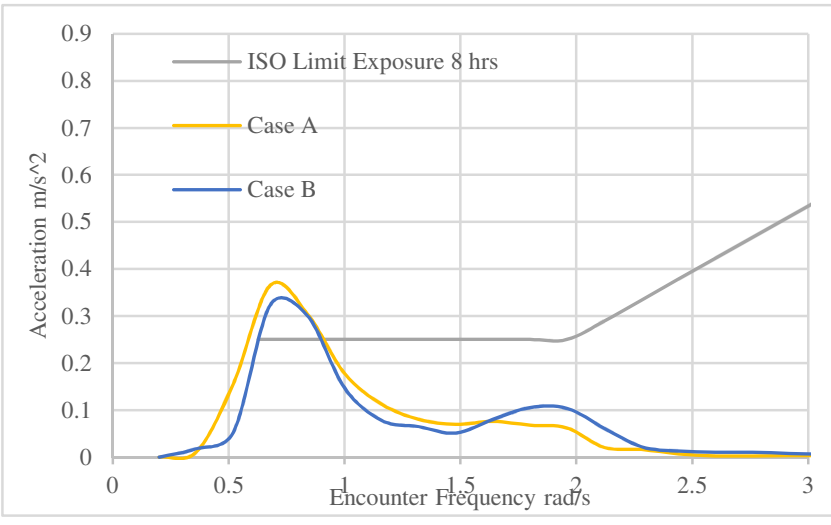

Fig. 10. Bridge in very rough head waves

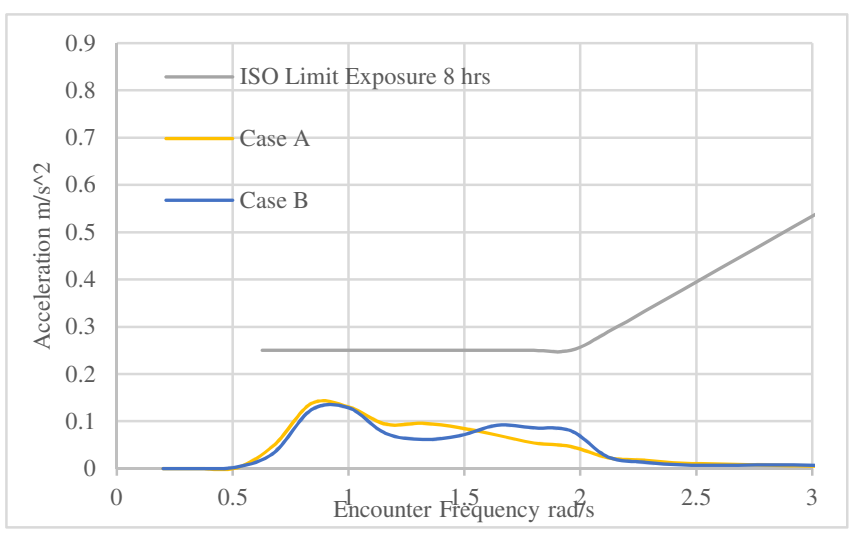

Fig. 12. Accom. 1 in moderate bow quartering waves.

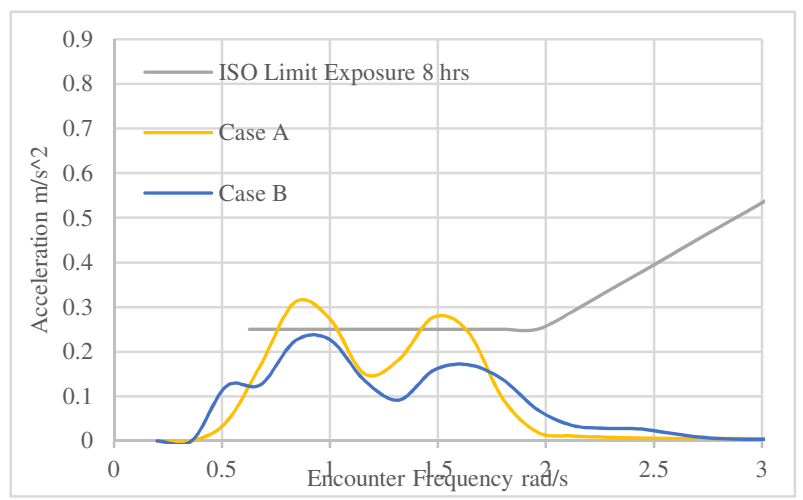

Fig. 14. Accom.1 in rough beam waves.

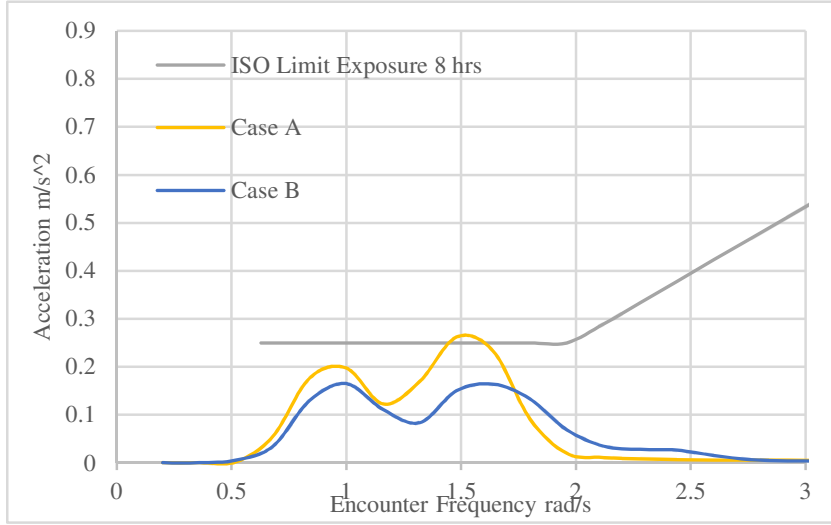

Fig. 11. Accom. 1 in moderate beam waves.

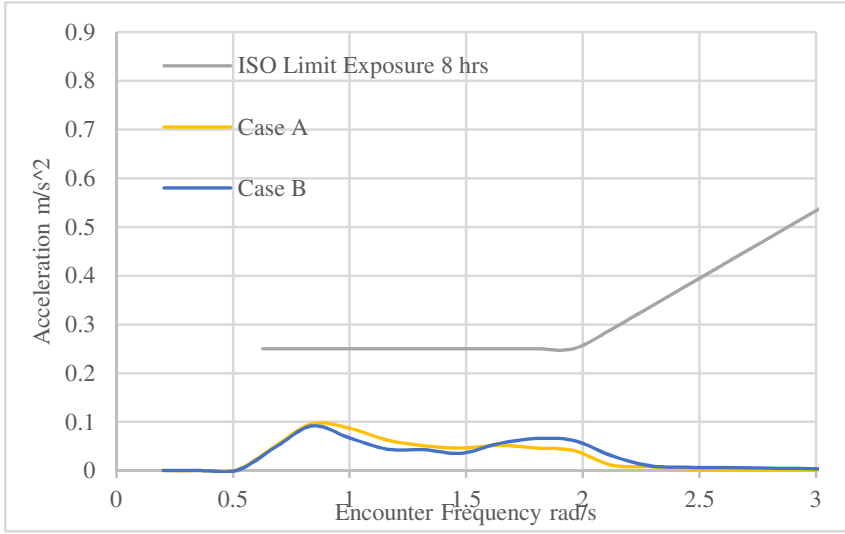

Fig. 13. Accom. 1 in moderate head waves.

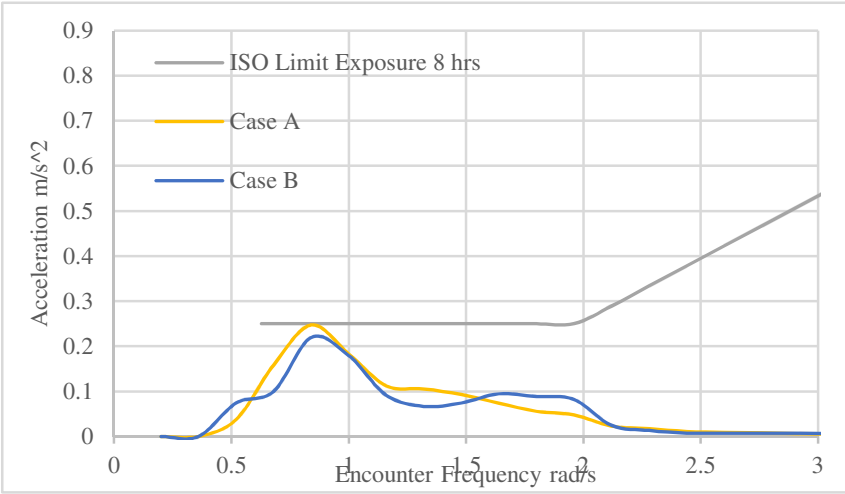

Fig. 15. Accom. 1 in rough bow quartering waves. 


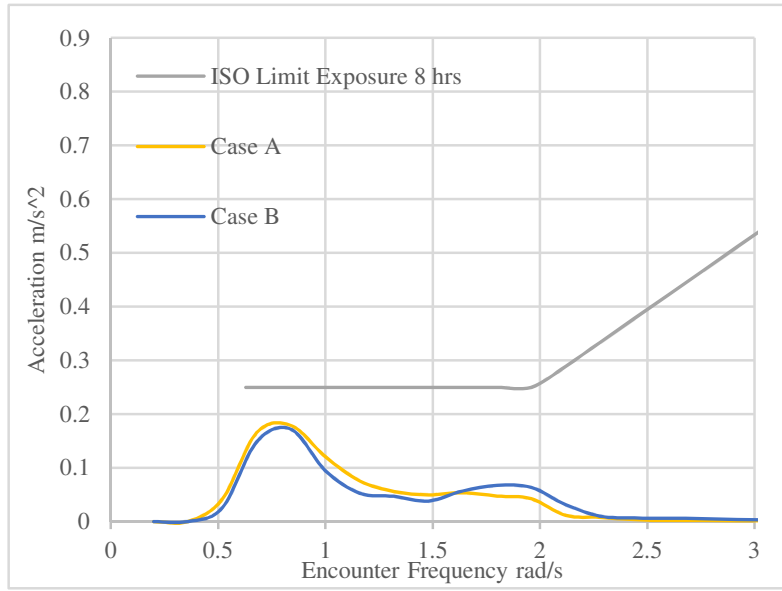

Fig. 16. Accom. 1 in rough head waves.

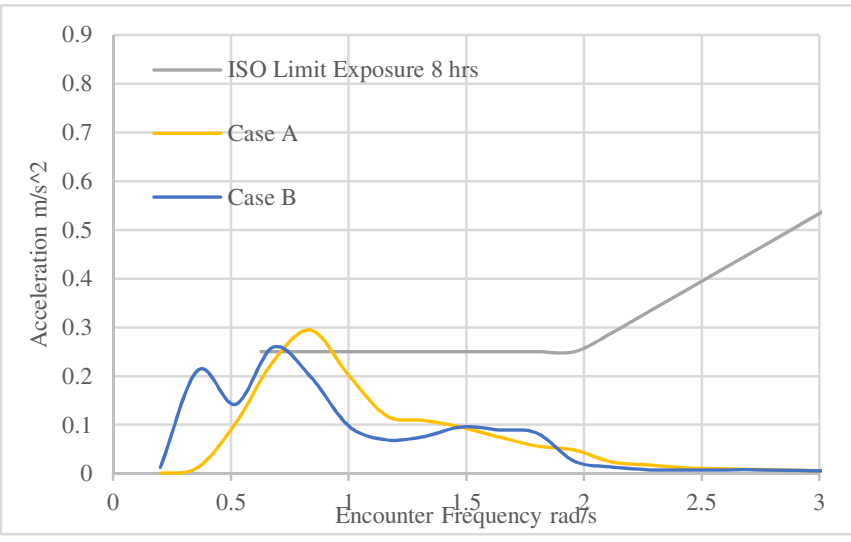

Fig. 18. Accom. 1 in very rough bow quartering waves.

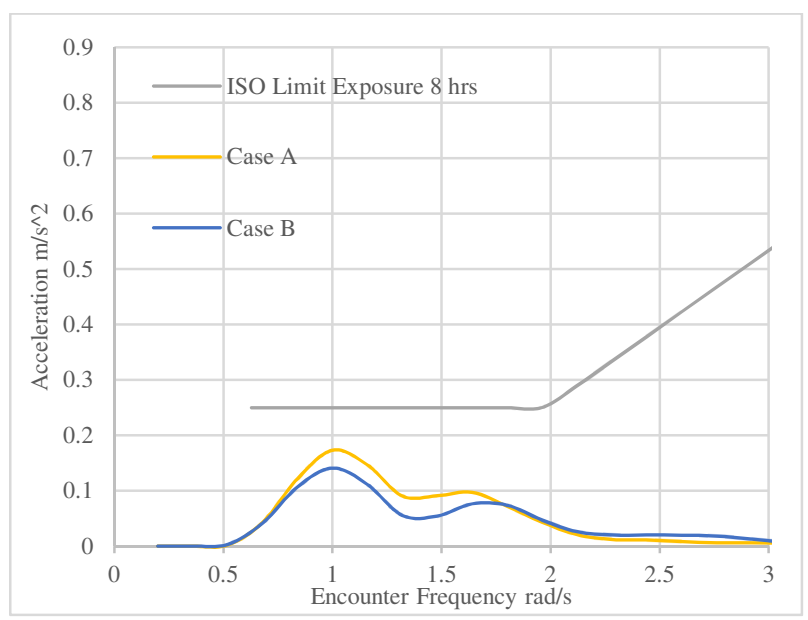

Fig. 20. Accom. 2 in Beam moderate waves.

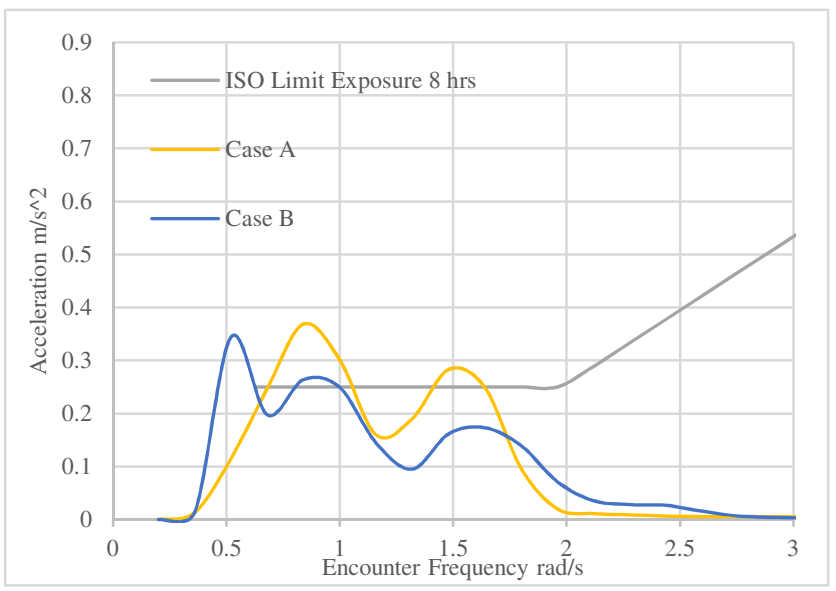

Fig. 17. Accom. 1 in very rough beam waves.

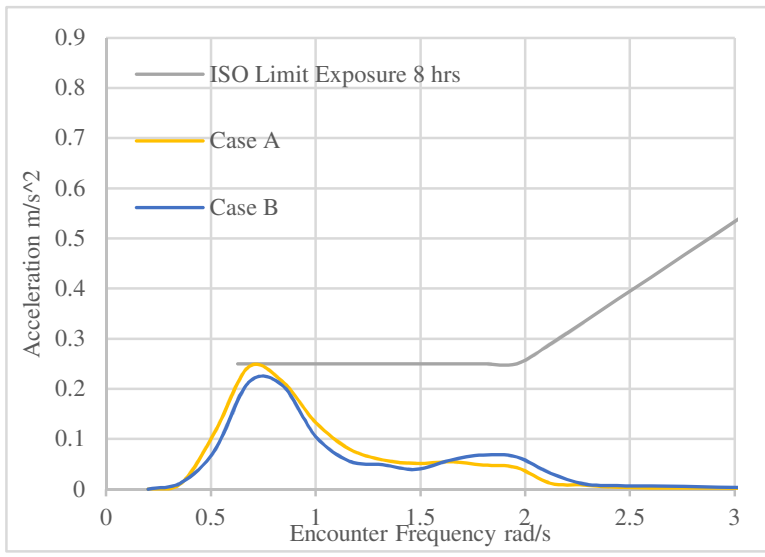

Fig. 19. Accom. 1 in very rough head waves.

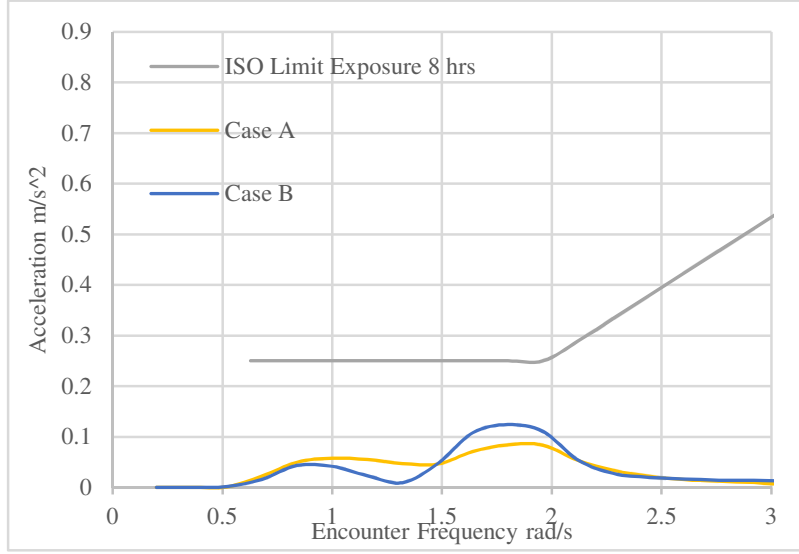

Fig. 21. Accom. 2 in bow quartering moderate waves. 


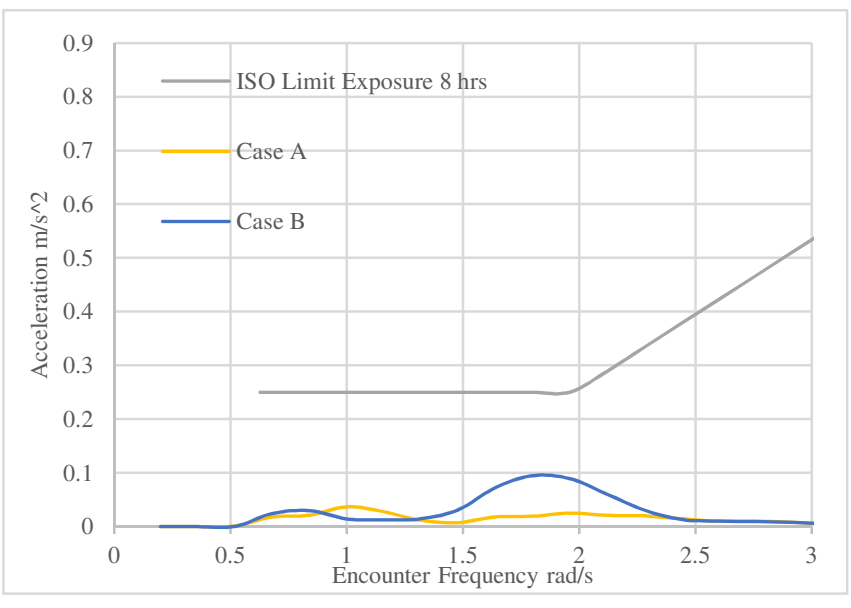

Fig. 22. Accom. 2 in head moderate waves.

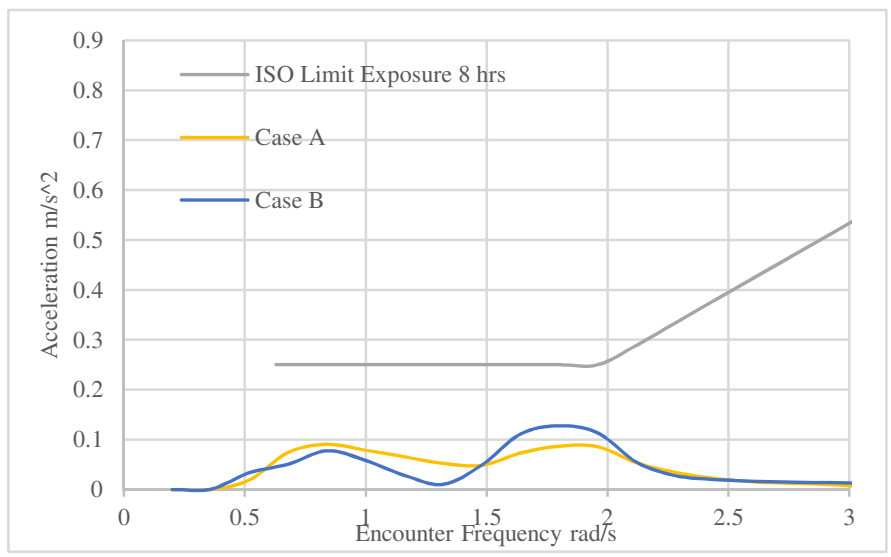

Fig. 24. Accom. 2 in bow quartering rough waves.

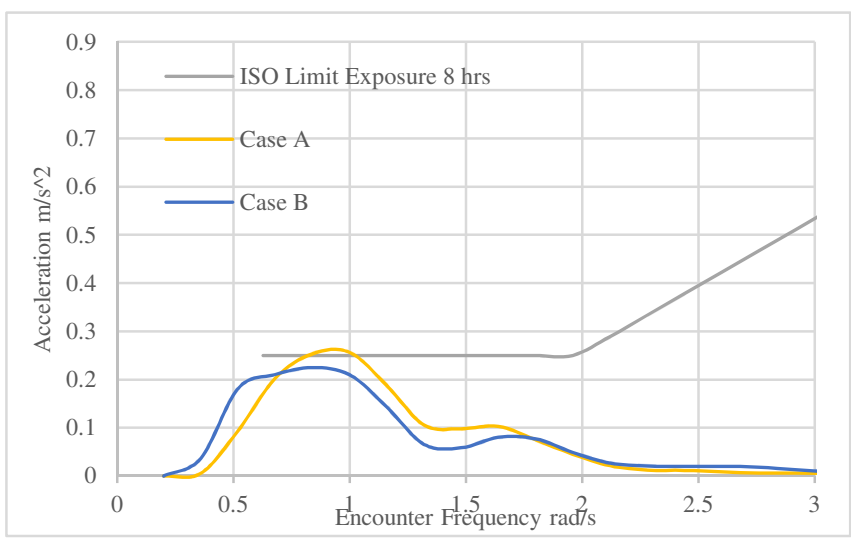

Fig. 26. Accom. 2 in beam very rough waves.

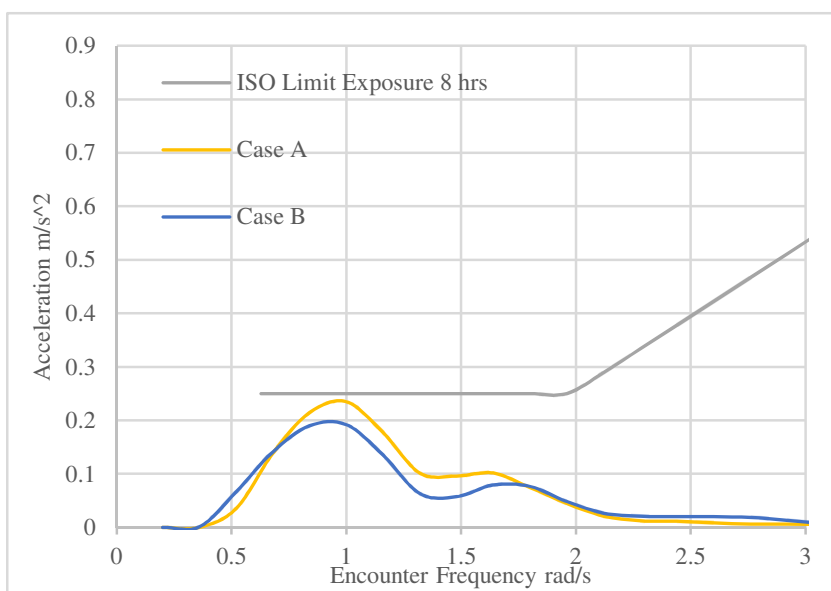

Fig. 23. Accom. 2 in beam rough waves.

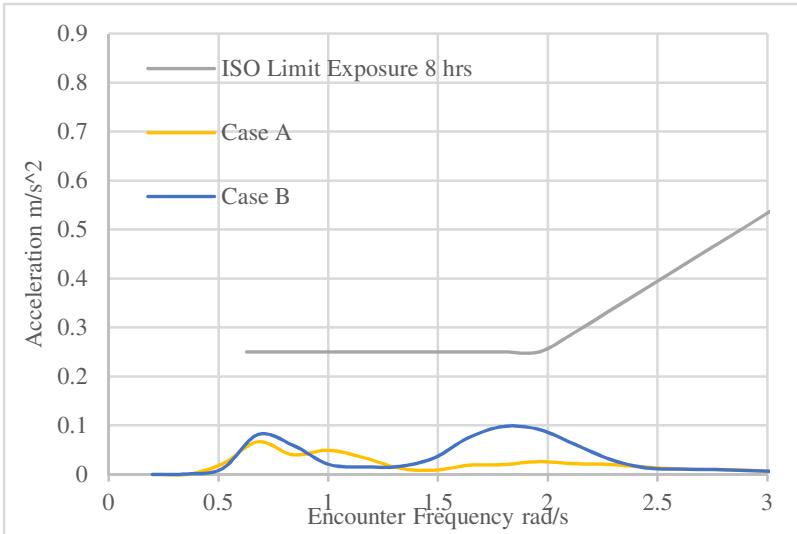

Fig. 25. Accom. 2 in head rough waves

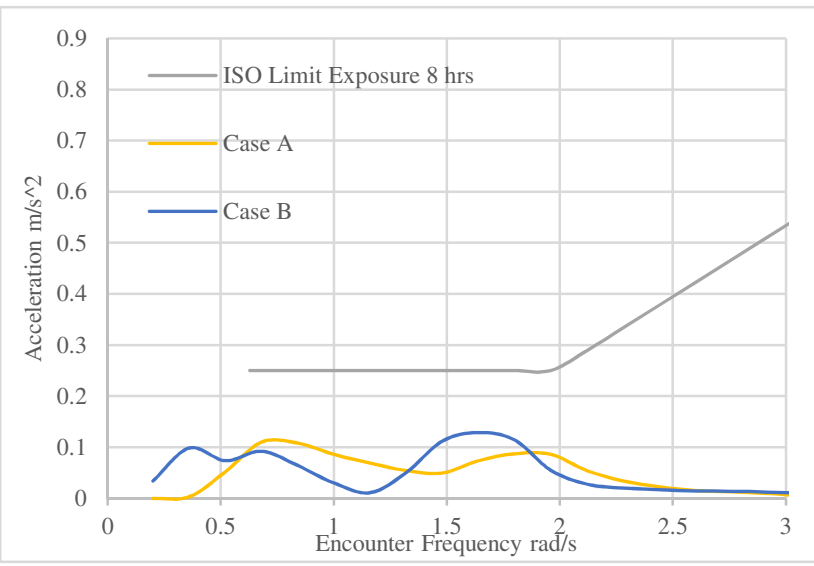

Fig. 27. Accom. 2 in bow quartering very rough waves. 


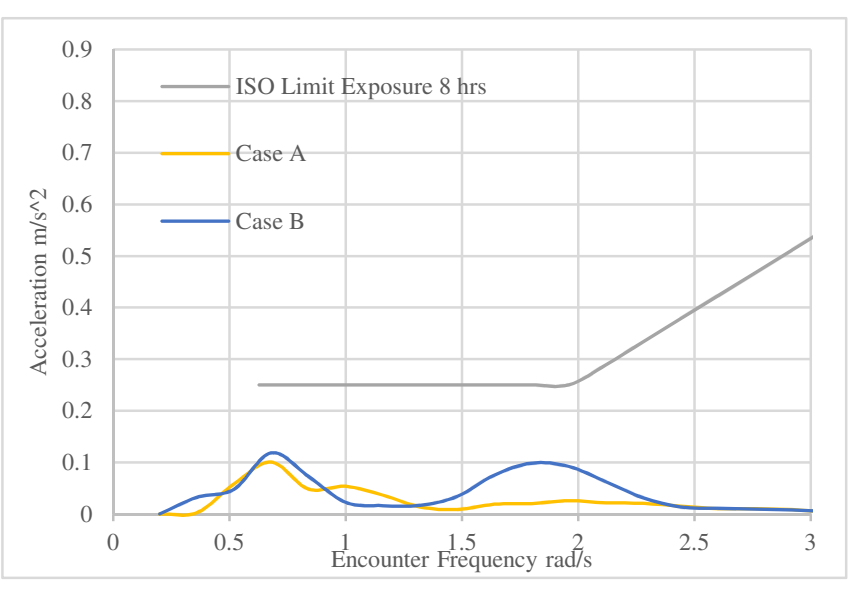

Fig. 28. Accom. 2 in head very rough waves.

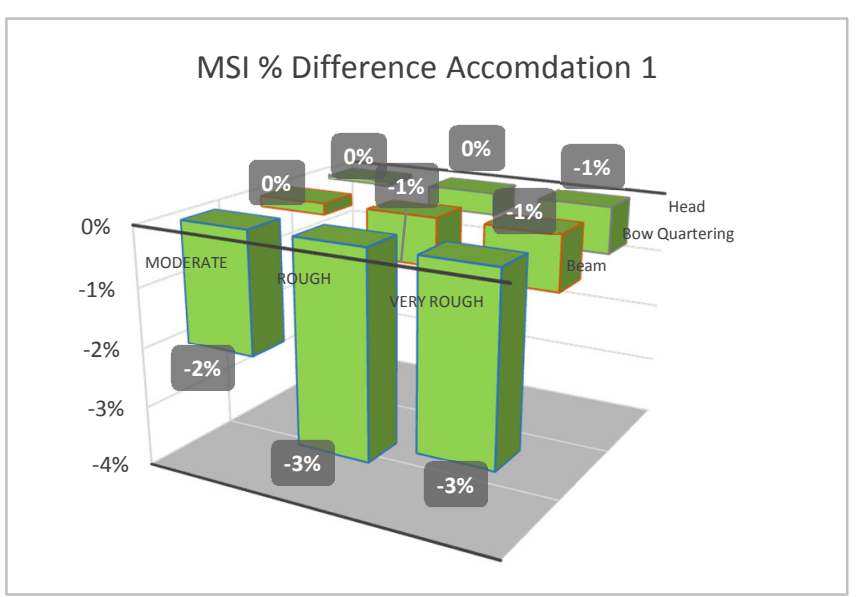

Fig. 30. Accommodation pt.1 MSI \% Difference.

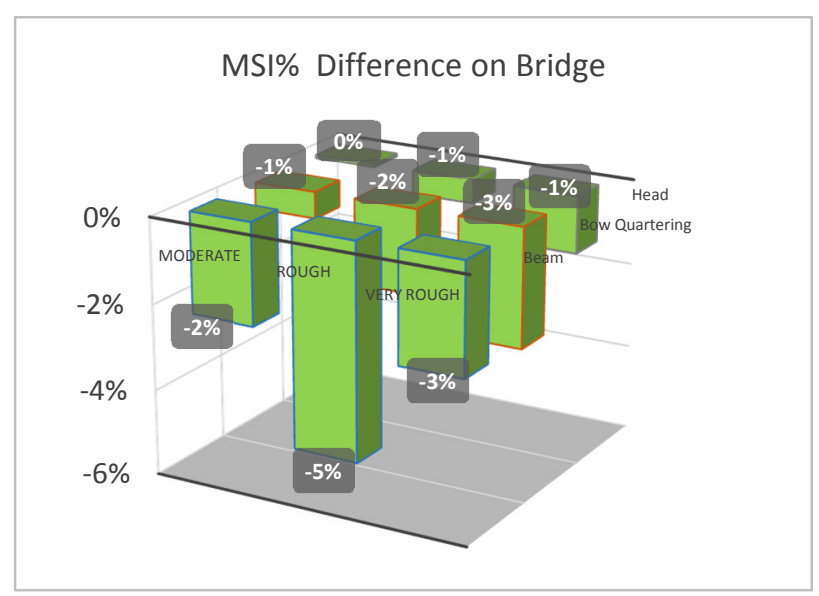

Fig. 29 Bridge Pt. MSI \% Difference.

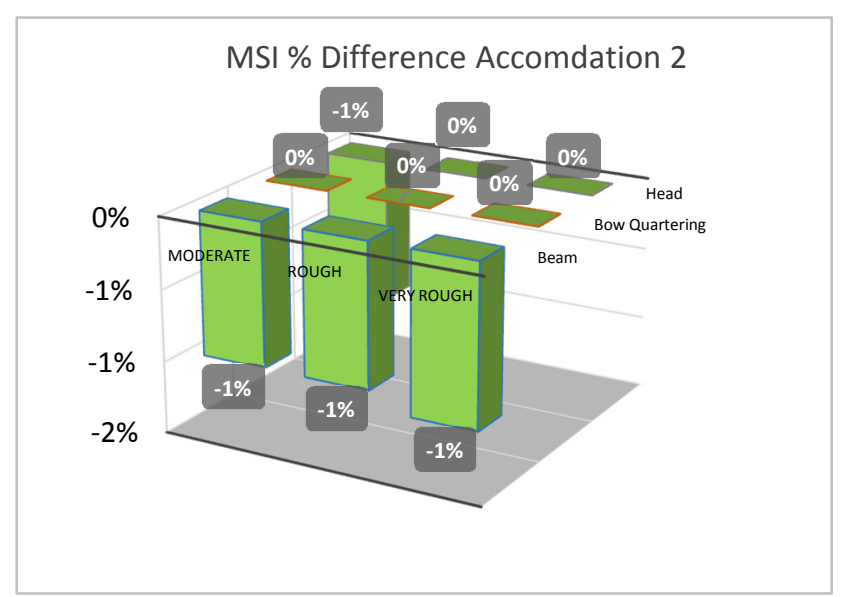

Fig. 31. Accommodation pt.2 MSI \% Difference. 